\title{
Embracing Quality with Design Thinking
}

\author{
Mark F. Tannian
}

\begin{abstract}
Developed outcomes that depend upon software can be of such quality that end users do not merely accept the product or service, they embrace it. The product or service is of such a quality that end users are excited, inspired, motivated, committed, or possibly relieved to be using the software directly or indirectly (i.e., an embedded component). Achieving embracing quality requires understanding user needs and desires as well as their environmental contexts and accommodating these understandings within the development practice. Design thinking is one approach to deliver products and services grounded in a user-informed development process.
\end{abstract}

Keywords Human-centered design · User-centered design · Design · Design thinking · Embracing quality · Quality · Prototype · Iterative design · Convergence quality · Collaboration

\section{Introduction}

Developed outcomes that depend upon software can be of such quality that end users do not merely accept the product or service, they embrace it. The product or service is of such a quality that end users are excited, inspired, motivated, committed, or possibly relieved to be using the software directly or indirectly (i.e., an embedded component). Moreover, the software development outcome has enabled end users to possibly do new things, derive pleasure from owning and using it, or is able to perform personally significant tasks more easily. The level of satisfaction is such that they have an affinity for what your team has produced. Think about those things you have and the activities you do that instill happiness, are fun, or improve your personal and work life. Would you say that is a quality worth achieving? This quality is being called embracing for this discussion.

M. F. Tannian

RBCS, Inc., Bulverde, TX, USA

(C) The Author(s) 2020

S. Goericke (ed.), The Future of Software Quality Assurance, https://doi.org/10.1007/978-3-030-29509-7_13 
Achieving embracing quality requires understanding user needs and desires as well as their environmental contexts, and accommodating these understandings within the development practice. Quality function deployment (QFD) introduced by Shigeru Mizuno and Yoji Akao sensitized designers to the needs of the customer, and this practice helped introduce the term "voice of the customer." The QFD approach brings customer satisfaction forward early into manufacturing or development processes [1]. Another approach to understanding the user is inspired and informed by the design community. This approach is called "design thinking."

In the next section, a brief expansion on embracing quality is presented. The following section will introduce design thinking. The fourth section will describe design thinking's role in bringing about embracing quality. The fifth section raises potential challenges related to design thinking. The final section will end the chapter with some concluding thoughts.

\section{Embracing Quality}

Embracing quality is a convergence quality that emerges from other emergent qualities, such as reliability, security, privacy, usability, and performance. For our purposes, a convergence quality is a quality that results from the integration of the user with the product or service. The user completes the technology and the resulting combination achieves desired value. The synergy between technology and user is such that the user finds great satisfaction, enjoyment, and may even experience flow [2] from using this technology. This synergy may allow the user to function as if the technology were an extension of her or him.

Embracing as a quality is not static and the level of this quality achieved may not be universal within a market. Culture strongly influences taste, aesthetics, personal values as well as the verbal and nonverbal means by which we communicate. A product or service that achieves embracing quality within a market may lose it over time. Certainly the opposite may happen where a product achieves greater embracing quality in the future. Product and service qualities such as reliability, fitness-for-purpose, security, usability, and performance change due to development practices and external factors, such as market changes, cultural sensitivities, and security threat landscapes. These are significant reasons for why innovation and quality assurance are necessary to achieve embracing quality. This chapter will not explore how to measure or define the gradations within embracing. Suffice it to say that embracing is not strictly a binary value (i.e., rejected or embraced). Some examples of products and services that have achieved embracing at one point in their history are Word Perfect, Sonic the Hedgehog, Apple iPhone, and Uber.

Embracing quality is an outcome that is dependent upon a product or service exhibiting sufficient levels of product or service quality as deemed important by users. ISO 25010:2011 calls out the following as system or software product quality dimensions: functional suitability, performance efficiency, compatibility, usability, reliability, security, maintainability, and portability [3]. Figure 1 depicts an alterna- 


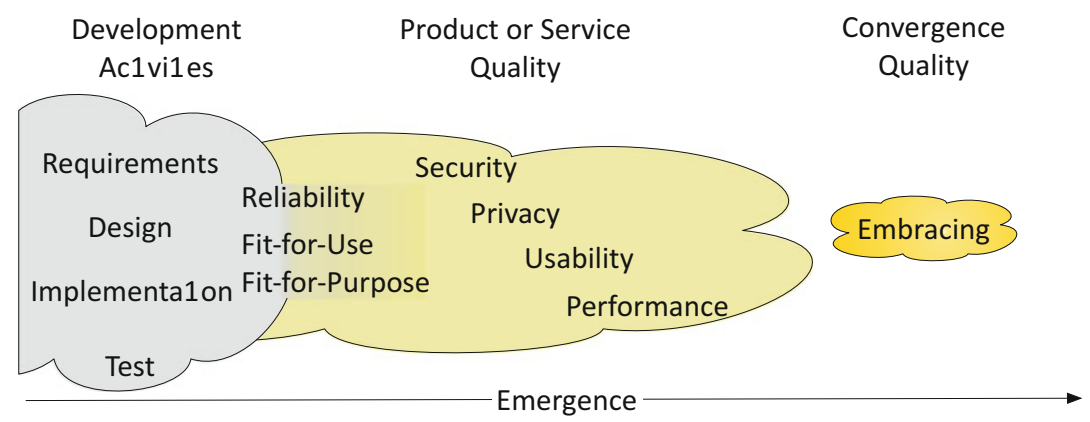

Fig. 1 Relationship of embracing quality to development activities

tive progression of qualities as they result from development activities. Admittedly Fig. 1 is not exhaustive in presenting all software or system qualities, an abbreviated collection was chosen for the sake of visual clarity and space. Figure 1 suggests that development activities primarily focus on reliability, fitness-for-use, and fitnessfor-purpose. On some projects, requirements are written and development efforts are allocated to address aspects of the qualities of security, privacy, usability, and performance; however, the cohesive and comprehensive sense of these qualities are emergent. A product or service is unlikely to succeed without sufficient reliability, fitness-for-use, and fitness-for-purpose. These are immediate and necessary qualities to address by any development team. The requirements and efforts to achieve these qualities in turn influence the achievement of overall security, privacy, usability, and performance. The complex interplay among qualities, such as security, usability, and performance, further complicate achieving these quality dimensions.

Social dynamics such as peer pressure, status seeking, opinion influencers, and user ratings influence initial and ongoing interest in a product or service. Product managers and development teams must seek to achieve adequate levels of and balance among product or service qualities (e.g., security, privacy, usability, etc.); however, embracing quality is not completely in their control to achieve.

The "lean" software and business development concepts of minimal marketable feature (MMF) and minimal viable product (MVP) are by their definition minimizations of time, resources, and investment. Teams working towards these optimal outcomes are essentially seeking the tipping point of what is minimally marketable and minimally viable and what would be insufficient. This tight margin between sufficiency and insufficiency increases the sensitivity of qualities like fitness-forpurpose to the judgment of those responsible for defining what is minimally marketable and minimally viable for the audience being anticipated. The "voice of the customer" is essential for these judgments to be grounded in actual expectations.

Although a team's efforts may be deep within the technology stack, each work product influences qualities such as security, privacy, usability, and performance that will in turn influence the user's experience. It is important for team members to recognize how each team's contribution fits into the overall design and what role 


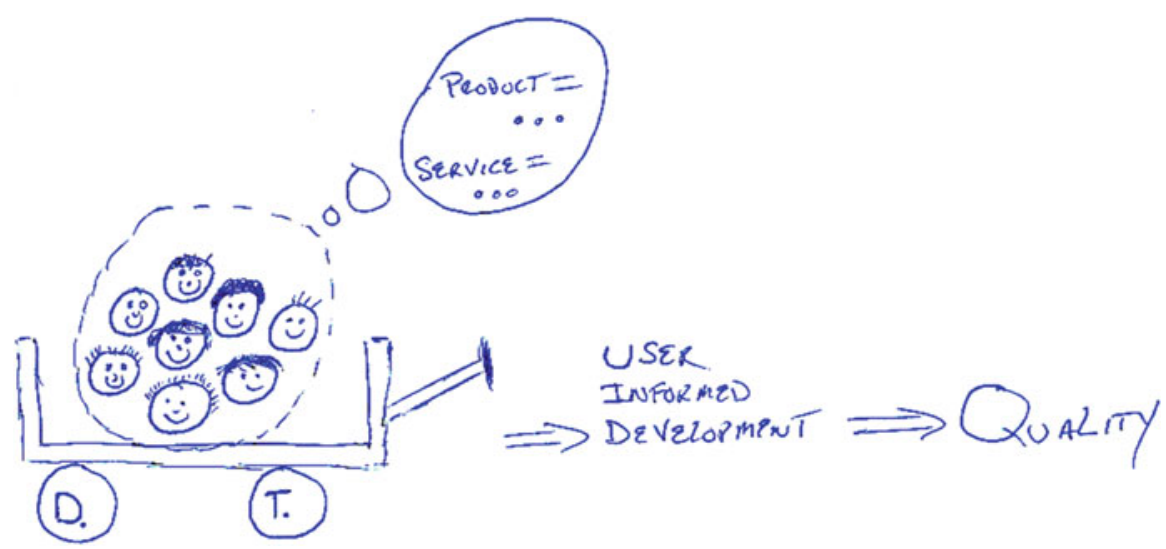

Fig. 2 Design thinking as a vehicle to achieve user-informed development and quality [in a visual thinking style]

the product or service plays in the end user's life. This understanding is needed to influence the numerous subtle decisions being made as they implement and test. Promoting user and overall solution awareness within development teams will assist members to recognize the impact of their efforts (Fig. 2).

Design thinking is a promising method for delivering products and services grounded in a user-informed development process. A brief introduction to design thinking is provided next.

\section{Introducing Design Thinking}

There are a number of books available that explore design thinking, such as [4, 5]. After reading Nigel Cross's Design Thinking [6] and Jeanne Liedtka and Tim Ogilvie's Designing for Growth: A Design Thinking Tool Kit for Managers [4], you may wonder what design thinking really means. There are two schools of thought that have adopted the term "design thinking." Cross is a member of a discipline of inquiry that explores design and how designers (e.g., architects, industrial designers) do what they do. The second school attempts to provide a bridge between designerly thinking and successful business innovation. To be clear, design thinking in the remainder of this chapter is that which enables businesses to be successful innovators. An accessible introduction to design thinking is the $A 4 Q$ Design Thinking Foundation Level syllabus [7].

\subsection{Fundamental Concepts}

There is no single approach to design thinking. However there are common aspects among the well-established approaches. Design thinking at its core is a user- 
centered design approach. A critical objective is to understand users and their objectives, needs, and impediments as they relate to what is being designed. Design is iterative and eventually converges on a final design by repeating the pattern of learning-making-evaluating as well as the pattern of divergent thinkingconvergent thinking. The design team implements multiple alternative designs and allows users to experience these alternatives. The team adopts user insights as the design progresses. Design thinking relies heavily on the team's ability to work, explore, fail, and learn together. An underlying assumption is that initial designs are somehow wrong. Each design alternative is a good guess, but only a guess to which the team should not be overly committed. The principle "fail faster, succeed sooner" (attributed to David Kelley) is inherent in design thinking [8]. Teams should recognize the limits of analysis and rely on experimentation to achieve understanding. These experiments utilize prototypes that progress in fidelity from paper drawings, Lego blocks, and pipe cleaners to functional product as the team approaches its goal of delivering a product or service design.

\subsection{Design Thinking Resources}

Innovation is necessary for nearly all businesses, but it is not guaranteed to occur for all. Fundamentally, innovation is finding a viable solution to a problem for the first time. A design team may not be the first to try. However, if they are successful, they will be the first to discover a previously unknown answer. Innovation using design thinking results from a clever fusion of resources. People, place, parts, and partnership are necessary for design thinking to thrive.

In practice, designing innovative products and services requires a team of designers. In this context, the term "designer" is a role, not a designation, resulting from training in the design fields. Each member should be an expert in relevant technologies or fields of study or areas of the business. Diversity among members enables the team to propose a variety of and identify potential in candidate solutions. Each member needs to possess or be willing to develop the qualities of being observant, empathetic, attentive, and humble. These qualities are essential for each team member to learn throughout the design process as well as for the team to form common understandings.

With language and speech being limited forms of communication, visual thinking is an essential skill when communicating concepts and relationships that linearvocabulary-bound communication struggles to convey. Pictorial communication is less hindered by differences in personal history, culture, and language.

There will be mistakes and misunderstandings. It is important to "fail fast," learn, and adapt. The team should encourage thoughtful risk taking. Each member's contribution has the potential to tip the effort into a successful direction. The converse is also true in that suggestions may prove to send the effort astray. Therefore, the team needs to provide a safe supportive environment and be able to work together with shared purpose, flexibility, and urgency. 
Where this work is performed is integral to the process. This space is ideally well lit and flexible in terms of furniture and work surfaces. The workspace should facilitate collaboration and immersion. While onsite team members are actively working on the project, they should work in this space in order to be present for informal and possibly spontaneous exchanges. Having a stable location allows the team to place various project artifacts (e.g., prototypes, charts, drawings) in proximity to each other. Working in this space allows team members to recall and dwell on previous outcomes as they progress further along in design development. Prototype assembly and evaluation often takes place in this room. Specialized equipment may require prototype subassemblies to be constructed elsewhere. This may be a place where cooperating users meet with design team members. Depending on which design thinking techniques are used, it is helpful at times to have a space in which to assemble a gallery of ideas for collaborating colleagues and users to explore and consider. Anchoring the gallery in the team's designated space will likely improve activity logistics.

There is a strong drive within design thinking to "do" or "make." This mindset reinforces "fail faster, succeed sooner." When one is exploring the unknown, multiple quick experiments may quickly yield useful signals that will guide the design to success. In order to make, the team needs parts, materials, tools and talent. The talent component is addressed in part when forming the team; however, certain specialties may not be in-house or are not available for extended commitments to the project. Given the need for speed, variety, and volume of prototypes, the fidelity of the prototypes change as the design progresses. Fidelity is a term that relates to a prototype's approximation of a final finished product or service. A low-fidelity prototype focuses on large conceptual questions and often consists of rough drawn ideas or simple three-dimensional mockups. There is quite a bit of engineering undone at low fidelity. As the team makes deeper commitments to design alternatives the degree of fidelity increases, which is reflected in the level of engineering investment and operational sophistication of the prototype.

The team must consider the tradeoff between sophistication and conceptual agility as fidelity increases. Design thinking's goal is a user-centered nuanced understanding and design, and often the result is not a market-ready product or service. The team may realize significant shortcomings exist as user consultations progress. Investments in sophistication that does not directly influence the user experience or their task objectives are unlikely good design thinking prototype features. In many cases, design thinking yields mature materialized or implemented user requirements, but not necessarily a final product or service. Manufacturing engineering and production-grade software development processes are expected to follow.

Parts and materials are often generic or are repurposed store-bought items. Large format paper, white boards, colored pens and markers, paints, stickers, sticky notes, pipe cleaners, and Lego blocks are often used at low fidelity. Software development may start earlier than other technical disciplines because of the flexibility of programing and computing platforms. The team may seek to test a final design under close to real-world conditions prior to submitting the design and closing the design- 
thinking project. To that end, custom parts or subassemblies, such as enclosures and circuit boards, may be needed.

There are two essential partnership types. The first is related to the sponsoring organization. The design thinking team needs the support of the sponsoring organization in terms of budget, approach, schedule, and outcome expectations. The design thinking team is tailored to the project. The appropriate personnel may not initially work in the same business units or functions. The broader organization needs to be willing to direct talented individuals to the team. Failure to develop a viable design is a possibility the sponsor must accept. A well-run design-thinking project will yield intellectual capital in terms of market understanding, promising solution approaches, and awareness of technical challenges. If the sponsors remain committed to addressing the same problem or a redefinition of the problem, the knowledge gained has the potential of directing the next effort away from pitfalls and towards promising notions that otherwise would not be known.

The second type of partnership is between the design thinking team and cooperating users. Users are essential. They are the source of the signals that the team collects and analyzes. These signals will indicate what does not work, nudge the design towards what does, and expose realities of the problem that could not be discovered without them. Users must be candid, honest, and be of goodwill when communicating their impressions and insights. Depending upon the nature of what is being designed, the sponsoring organization and design team are placing significant trust in these users. This trust relates to the relevance and reliability of their feedback as well as their discretion. Most likely each user will sign a confidentiality agreement; however, enforcing it may be difficult. In some cases, the loss from a breach of confidentiality may be beyond any realistic compensation from a jury award or legal settlement.

\subsection{Design Thinking Approaches}

There are multiple documented approaches to design thinking. The Design Council believes there is no one ideal design thinking approach [9]. The primary reasons for this are that business environments are undergoing continual change that prevents an ideal approach from emerging, and the need for businesses to adapt design thinking to their business makes their practical design thinking approach unique. There are several well-known general design thinking approaches. The Design Council introduced the Double Diamond approach [10]. Stanford d.School introduced their 5-stage approach [11]. Liedtka and Ogilvie introduced the Designing for Growth approach [4]. Although each organization will likely approach design thinking differently, it is informative to explore established general approaches.

The Double Diamond approach developed by the Design Council has four stages. The diamond in the approach title refers to a visual metaphor that represents the natures of the four stages. The depiction in Fig. 3 provides a visual that expands upon the diamond metaphor. Each stage of the four stages of Discover, Define, 


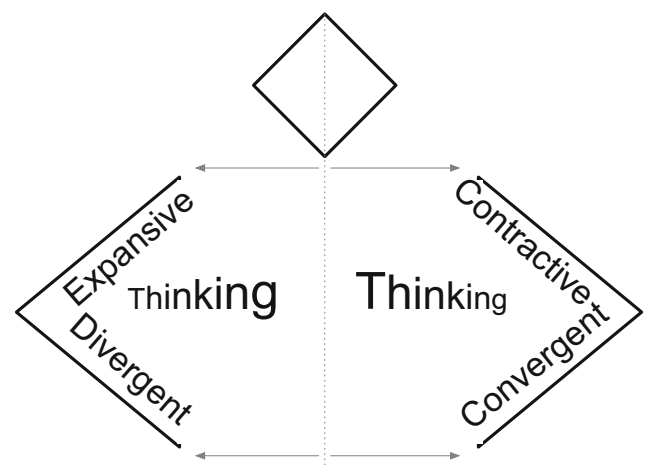

Fig. 3 Explanation of the diamond metaphor

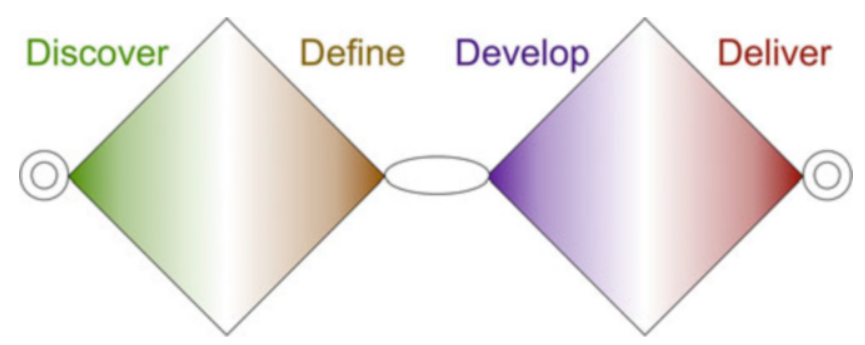

Fig. 4 Double Diamond approach

Develop, and Deliver conceptually align to each of the four left-right halves of two diamonds (Double Diamond) as shown in Fig. 4. The Discover stage is expansive in approach, seeking out and gathering what is known and knowable about the problem to be addressed by the intended innovation. After having assembled a broad range of inputs, the Define stage is engaged and the content is distilled and synthesized into a Design Brief. Informed by the Design Brief, the Develop stage uses expansive or divergent thinking in order to create, evaluate, and refine multiple design options. In the final stage, Deliver, a design is selected and is made ready for use. Design Council provides a collection of process methodologies to facilitate the completion of each stage.

The Stanford 5-Stage d.School approach is a bit fluid. At times practitioners of the Stanford approach introduce a sixth stage. Adaptability is an inherent spirit among those who apply Stanford's approach. One popular layout of the approach consists of the stages Empathize, Define, Ideate, Prototype, and Test [11]. An optional addition is the stage called Notice. This stage is oriented to identifying or noticing the initial problem to be explored before one can proceed to empathize, define, and so on. The overall flow through the stages is as previously listed. However, at a given time within a project it may be appropriate to revisit or jump ahead along the sequence of stages. Beyond describing the mechanisms with which to execute design thinking, Stanford d.School promotes the need for an appropriate 
mindset among team members. The mindset animates their process and is useful to consider for adoption generally. Some of the mindset attributes are "human centered," "bias toward action," "radical collaboration," "show don't tell," and "mindful of process."

The last approach we will explore is Designing for Growth developed by Jeanne Liedtka and Tim Ogilvie [4]. This approach is designed to ask and answer four questions in dedicated stages. These questions are in order "What is?," "What if?," "What wows?," and "What works?." Their approach and their motivations for developing this process are closely aligned with the business need to generate new business value. Like the other two general processes, the starting point is the first stage listed and the successful stopping point occurs when "What works?" is truly completed. Iterations within and between these stages are likely necessary. In order to make these stages actionable, a set of ten tools have been described [4]. These in turn have been expanded upon by techniques that have been documented in a workbook [12]. Unlike the Double Diamond process, the result of this process is not a market-ready product or service. Liedtka and Ogilvie are committed to the need for learning up until the very end. The "What works?" ends with a limited and controlled market test that emulates practical conditions that may uncover significant challenges. A highly functional preproduction prototype is developed that enables the team to uncover flaws that need to be corrected prior to fully committing to a market or production-ready offering.

\section{Design Thinking's Role in Quality}

By using design thinking to focus on users and their experiences, the team has a means to gauge the design's potential along the embracing quality continuum. Iterating multiple design approaches through the make-learn-evaluate cycle with users provides the design team multiple opportunities to identify disagreeable aspects of designs, understand users' interests, calibrate outcome expectations, and prioritize promising elements of a design. By remaining agile and open to change, design thinking teams avoid prematurely committing to assumptions, understandings, and preferences that do not align with actual use, expectations, and users.

Design thinking directs development efforts to produce tangible design alternatives for user evaluations. Having a concrete representation of design ideas allows users to experience ideas; provides a common visible point of reference from which to offer and interpret feedback; and acts as a baseline from which to suggest revisions or alternatives. Figure 5 depicts active design thinking efforts as a central motivating force for development activities. Various quality objectives must remain unaddressed or limited in order to maintain speed and responsiveness. Many underlying infrastructure components up to the point of a premarket test will unlikely experience load and diverse usage patterns that deviate from guided user evaluation session objectives. The limited range of usage allows for various quality 


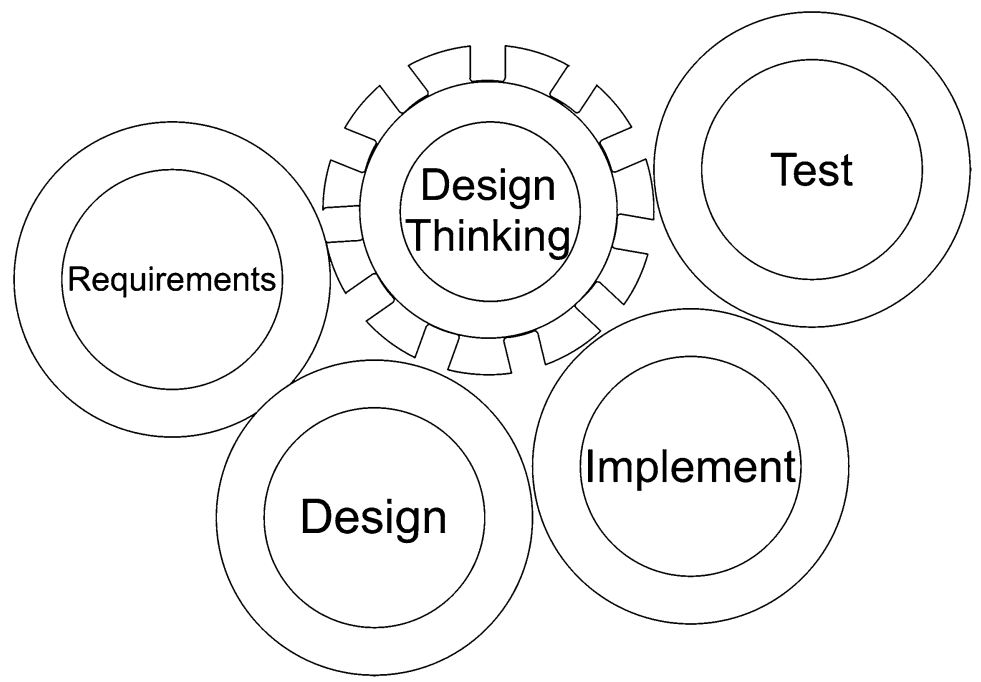

Fig. 5 Design thinking is central to the design candidate development processes

objectives to be avoided or postponed. Only in the limited premarket evaluation will users have an opportunity for intense independent, self-directed use of the product or service.

Assuming all goes well, the design thinking outcome is a highly promising prototype or proof of concept. The result will likely be limited in production level qualities, such as resiliency, reliability, and performance. Production shortcomings in these behind-the-scenes functional qualities will undermine the goodwill provided by a design's potential. Imagine if your ride-hailing app failed to coordinate a ride successfully $20 \%$ or more of the time. The novelty of a ride hailing app will compensate for premarket quality during final user evaluation. However, if the app is being marketed beyond a controlled evaluation, poor reliability will not be well received. How many times can users be disappointed in performance or reliability before the level of embracing quality slips towards rejected? Consider proposals to deploy design-thinking prototypes for general use carefully.

Having obtained experimental evidence of what feature functionality and feature sets are minimally sufficient, the user experience-oriented specifications of MMFs and MVP are likely to align with the market. Ideally the outcome of utilizing a MVP strategy is to earn revenue sooner, minimize costs, and maximize return on investment. However, there is likely to be significant tension as to what constitutes minimally necessary and sufficient for requirements that will address qualities like reliability, fitness for use, security, privacy, and performance. Design thinking is unlikely to produce much more than limited considered opinion on the significance and character of qualities users do not directly experience or recognize in context. Products and services that can be managed with continuous deployment may be 


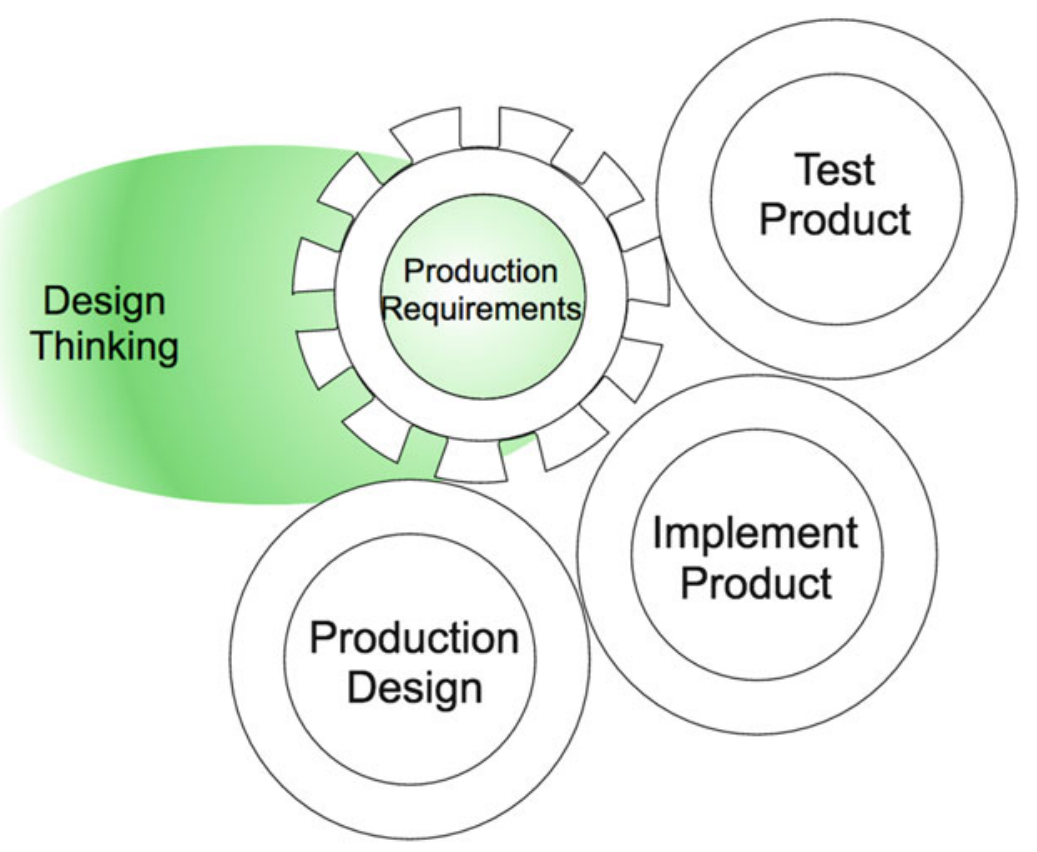

Fig. 6 Design thinking informs production requirements that govern production design, implementation, and testing

deployed relatively early with regular revision. Continuous deployment is less viable for products that at best can be patched or updated once a month.

Once the design thinking phase has completed, the interactive dynamic between users and the design for the most part ends. The design outcome provides an established set of user-facing requirements that need to be implemented and tested to accepted production quality. Given the speed at which prototype code is written, its base may only be partially salvageable. The languages and libraries chosen may have enabled prototyping speed and flexibility. Now knowing what needs to be implemented, the language and library selections may need to be revisited in order to provide a more manageable, reliable, secure, and computationally efficient foundation. By having senior developers participating on the design thinking project, various development conventions and tool chains used in standard development projects are more likely to be used during prototype implementation, thus making reuse more feasible. Figure 6 shows design thinking as a launch point that influences production requirements, but it is no longer a dynamic component among production development activities. The central motivating force is the production requirements activity, which will develop new requirements necessary for the result to be of sufficient reliability, fitness for use, security, privacy, usability, maintainability, and performance to be successful in the marketplace or in production. 


\section{Challenges of Design Thinking}

Design thinking does not mitigate all the risk of innovation. At times it may appear to make innovation more risky. An innovation that involves people is best done with input from the affected users. Avoiding the user community results in a design that is based on assumptions that lack validation prior to release. These assumptions start with the problem definition and continue to the ultimate design outcome. Design thinking provides an approach to gathering, interpreting, and responding to user insights. This section explores some of the challenges design thinking either introduces or does not fully resolve for the design team.

Design thinking is not a cooking recipe (i.e., gather listed measured ingredients, prepare ingredients as specified, assemble, cook, and enjoy) for innovative success. The dimensions of problem domain, team composition, level of design thinking expertise, cooperating users, available materials and parts, supplier relationships, market timing, market conditions, budget, business climate outside of the team, and the state of the art individually and in combination may fatally hinder the design project or the ability to realize monetary value or brand elevation from its result.

Diversity of users within the targeted market is desired in order to recognize the breadth of preferences, task variety, and user challenges within the problem domain as well as challenges with the design alternatives. Some of the most informative users are those who "suffer" from "restless-user syndrome." This nonmedical condition presents itself as perpetual dissatisfaction with the products and services at hand combined with imaginings of capabilities, features, and qualities not yet considered or have been discarded. An "afflicted" person understands the task objectives and that these tasks are largely independent of technology, but technology strongly influences the manner in which a task is performed. Locating restless users for your cooperating user pool may not be easy; however, they are extremely helpful. Regular users are needed as well. They are able to share with the team reasonable and useful perspective on what is present in an alternative. However, a restless user will also guide the design team deeper into the problem domain or suggest things not previously considered. A challenge is to find a diverse set of restless users.

Basing design decisions on user input can be puzzling. Unlike electrical and mechanical measurements like speed, distance, height, or voltage, locating and interpreting relevant insights and relating them to each other is relatively more complicated. User-based signals are embedded in noise of uncertainty, unique personal preferences, distracted thought, limited imagination, inconsistent rapport, language shortcomings, and inter- and intra-user inconsistency. Team members familiar with interpreting user session results will be needed to identify commonality, useful suggestions, and guiding direction. 


\section{Conclusions}

Embracing quality is a convergence quality that results from the integration of the user with a product or service. This quality emerges as a result of the user's intellectual and emotional response to accomplishing desired tasks using the product or service. Moreover, embracing quality is an aggregation of the responses of multiple users over multiple uses. This quality indirectly influences revenue, brand, efficiency, and productivity.

Embracing quality is difficult to design for directly. This challenge results from it being an emerging aggregation of service or product qualities (e.g., performance, security) as well as being highly dependent on users. The greatest influence the design team may have on the user is through user experience design and instructional resources.

Often the design team must anticipate what the user truly wants, needs, and desires. Understanding these things requires that designers engage users during design. By utilizing design thinking, a design team is able to augment their efforts by allowing user insights to influence design by incorporating their preferences, criticism, and suggestions.

In order to achieve embracing quality, seek out users and allow them to: inform the problem definition, create an affinity with the designers, and help you help them. In other words, center your design on the user by utilizing design thinking or other user-centered approaches in order to improve the likelihood of market success.

\section{References}

1. Mazzur, G.: History of QFD - Introduction. http://qfdeurope.com/en/history-of-qfd/ (2015). Accessed 14 June 2019

2. Csikszentmihalyi, M.: Flow: The Psychology of Optimal Experience. HarperCollins, New York (2008)

3. ISO/IEC: ISO/IEC 25010:2011 - Systems and software engineering - Systems and Software Quality Requirements and Evaluation (SQuaRE) - system and software quality models. In: International Organization for Standardization (2011)

4. Liedtka, J., Ogilvie, T.: Designing for Growth: A Design Thinking Tool Kit for Managers. Columbia University Press, New York (2011)

5. Lewrick, M., Link, P., Leifer, L.: The Design Thinking Playbook: Mindful Digital Transformation of Teams, Products, Services, Businesses and Ecosystems. Wiley, Hoboken (2018)

6. Cross, N.: Design Thinking: Understanding How Designers Think and Work. Berg, Oxford (2011)

7. A4Q Design Thinking Foundation Level. https://isqi.org/us/en/a4q-design-thinkingfoundation-level (2018). Accessed June 142019

8. Manzo, P.: Fail faster, succeed sooner. https://ssir.org/articles/entry/fail_faster_succeed_sooner (2008). Accessed June 142019

9. Design Council. Eleven lessons: Managing design in eleven global companies - desk research report. Design Council (2007)

10. The Design Process: What is the double diamond?. https://www.designcouncil.org.uk/newsopinion/design-process-what-double-diamond. Accessed June 142019 
11. Doorley, S., Holcomb, S., Kliebahn, P., Segovia, K., Utley, J.: Design Thinking Bootleg. Hasso Plattner Institute of Design at Stanford. Stanford (2018)

12. Liedtka, J., Oglivie, T., Brozenske, R.: The Designing for Growth Field Book: A Step-by-Step Project Guide. Columbia University Press, New York (2014)

Open Access This chapter is licensed under the terms of the Creative Commons Attribution 4.0 International License (http://creativecommons.org/licenses/by/4.0/), which permits use, sharing, adaptation, distribution and reproduction in any medium or format, as long as you give appropriate credit to the original author(s) and the source, provide a link to the Creative Commons licence and indicate if changes were made.

The images or other third party material in this chapter are included in the chapter's Creative Commons licence, unless indicated otherwise in a credit line to the material. If material is not included in the chapter's Creative Commons licence and your intended use is not permitted by statutory regulation or exceeds the permitted use, you will need to obtain permission directly from the copyright holder. 